\title{
ARTICLE
}

\section{Radiological shielding design for the TOF polarisation analysis spectrometer Pelican at the OPAL reactor}

\author{
Tunay Ersez $^{\mathrm{a}^{*}}$ and Fernando Esposto ${ }^{\mathrm{a}}$ \\ ${ }^{a}$ Australian Nuclear Science and Technology Organisation, Locked Bag 2001, Kirrawee DC NSW 2232, Australia
}

\begin{abstract}
The shielding for the time-of-flight Polarisation Analysis Spectrometer (Pelican) located at the OPAL reactor (ANSTO) was designed using the Monte Carlo code MCNP 4B. The proposed shielding design has produced compact shielding assemblies, such as the Pelican monochromator drum, lead snout interfaced to guide shielding, and shielding around the Optical System, Sample Chamber and Detector Chamber Systems. These arrangements are consistent with safety requirements, floor load limits, and cost constraints. The neutron dose rates around the Pelican instrument were reduced to $<0.5 \mu \mathrm{Sv} / \mathrm{h}$ and the gamma dose rates were lowered to a safe working level of $\leq 3 \mu \mathrm{Sv} / \mathrm{h}$. The Optical System, with its components and the Detector Chamber were housed in borated polyethylene to shield from background signal noise.
\end{abstract}

Keywords: Monte Carlo; shielding design; dose levels; time-of-flight spectrometer; OPAL reactor;

\section{Introduction}

The Pelican instrument is a cold neutron time-of-flight (tof) spectrometer (with polarization analysis) designed to measure inelastic neutron scattering or to carry out spectroscopy. Tof instruments like Pelican have been incredibly productive scientifically and represent a good gateway into neutron spectroscopy for chemical, polymer and biological problems. But being a large tof spectrometer it is the "first" of its kind to operate with a polarized neutron-beam and also, for the polarization after the sample to be measured.

Pelican is the first instrument located on the CG1 neutron beam line in the Neutron Guide Hall of Australia's OPAL reactor [1]. The proposed layout of the instrument is shown in Figure 1, which consists of a monochromator system (3 highly oriented pyrolytic graphite (HOPG) monochromators, shielding drum, sample shutter and drive system), an Optical System (graphite and beryllium filters, 2 Fermi choppers, Soller collimator or polariser and spin-flipper, slit system and beam monitor), a Sample Chamber System (sample ancillary, radial oscillating collimator, beam stop and vacuum chamber) and a Detector Chamber System (200 detectors, vacuum chamber). A neutron guide of dimensions $200 \mathrm{~mm}$ (height) $\times 50 \mathrm{~mm}$ (width) feeds into the Pelican monochromator shielding assembly and it ends $\sim 200 \mathrm{~mm}$ from the triple focusing monochromator (take-off angles from $40^{\circ}$ to $140^{\circ}$ ).

Absorption and scattering of neutrons by Pelican's

*Corresponding author. Email: tunay.ersez@ansto.gov.au components will lead to significant shielding requirements and it is important to determine the amount of shielding required before construction. It will be difficult to install additional shielding later following radiation dose surveys.

In this paper we will present modeling and design of compact radiation shielding for the Pelican instrument. The acceptance criteria for the shielding design were (i) safety - dose rate $\leq 3 \mu \mathrm{Sv} / \mathrm{h}$ at external surfaces of the shielding assembly, (ii) floor load limit $<20$ tonnes $/ \mathrm{m}^{2}$, (iii) low cost and (iv) for maintenance purposes "easy access" to components of the instruments [2-4].

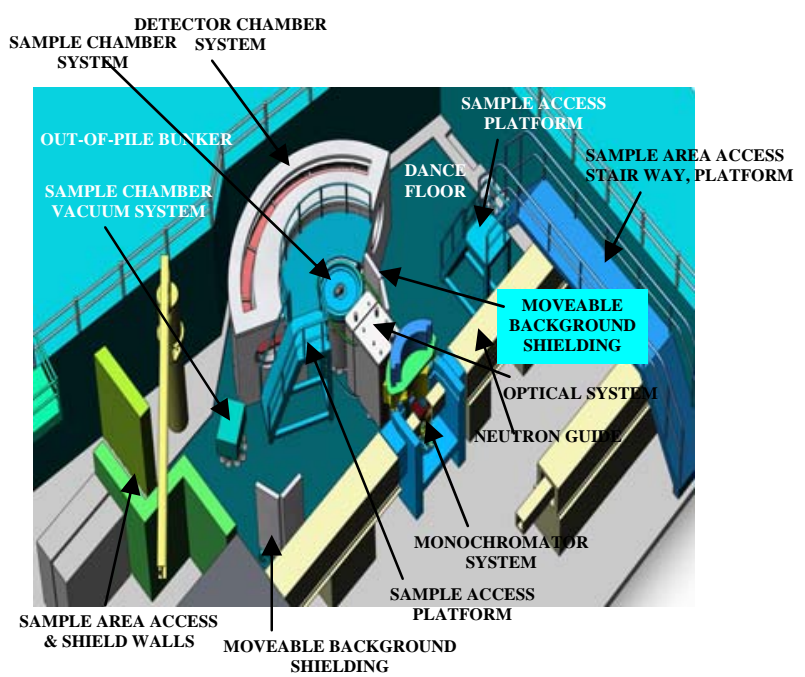

Figure 1. Proposed layout of the Pelican instrument with some of the components and neutron guide shielding. 


\section{Method for computational modeling}

A model of the proposed Pelican instrument shielding was constructed using MCNP 4B [5], which took into consideration acceptance criteria (ii) - (iv). The effectiveness of the shielding design to meet acceptance criteria (i) was estimated by the Monte Carlo Method, considering neutrons and generated prompt $\gamma$-radiation. In the modeling the average surface flux tally (type F2) and the average cell flux tally (type F4) were used and the geometry splitting variance reduction method was implemented. The cross sections were based on ENDF/B-VI neutron data and MCPLIB02 photon data. Conversion from radiation fluxes to doses is in correspondence with ANSI/ANS-6.1.1-1977 [6].

The geometry of the Pelican model is shown in Figure 2, which was constructed to match the design description given in the previous section. The model includes the neutron guides shielded by $\mathrm{Pb}(96 \%) \mathrm{Sb}(4 \%)$ walls of $120 \mathrm{~mm}$ thickness and has a concrete base support [7]. There was Boraflex ${ }^{\mathrm{TM}}$ cover on the Al-window at the exit of this guide, but not obstructing the beam path. The walls of the monochromator drum were $\mathrm{Pb}$ encased in steel, which is a combination of $\mathrm{Fe}$ $(10 \mathrm{~mm}$ thick $) / \mathrm{Pb}(200 \mathrm{~mm}$ thick $) / \mathrm{Fe}(10 \mathrm{~mm}$ thick $)$ and the inside of these walls, including the ceiling and base, were lined with Boraflex ${ }^{\mathrm{TM}}$ (10 mm thick). The front of the monochromator shielding facing towards the sample position, excluding Boraflex ${ }^{\mathrm{TM}}$, has an opening of 160 $\mathrm{mm}$ (height) $\times 100 \mathrm{~mm}$ (width) and its internal surfaces were lined with $5 \mathrm{~mm}$ thick Boraflex ${ }^{\mathrm{TM}}$. The monochromator drum was interfaced to the neutron guide shielding by a $\mathrm{Pb}$ snout (145 mm thickness).

The Optical System, with its components will be housed in $100 \mathrm{~mm}$ thick borated polyethylene to shield from background signal noise and similarly, the external surfaces of the Detector Chamber will be shielded with $100 \mathrm{~mm}$ thick borated polyethylene so as to minimize background signal noise.

Also, all the void regions in the model were filled with air except the evacuated areas in the neutron guide tubes, Detector Chamber and monitor.

The simulations were performed using two sets of neutron sources. The first was assumed to be a Maxwellian ( $\mathrm{T}=20 \mathrm{~K})$ mono-directional beam (along the neutron beam guide axis) and a flux of $6 \times 10^{11}$ neutrons. ${ }^{-1}$, which was used to determine dose rates at external surfaces around the monochromator drum and $\mathrm{Pb}$ snout. The second source was derived from McStas simulations [8] at sample positions for monochromator take off angles of $40^{\circ}-140^{\circ}$ and a flux of $4.8 \times 10^{8}$ neutrons. $\mathrm{s}^{-1}$, which was required to determine the dose rates at distances close to the Optical, Sample Chamber and Detector Chamber Systems and then decide on appropriate shielding against the scattering arising from the instrument components and sample.

Each dose rate was determined at the instrument areas and sectioned appropriately, up to a height of $2 \mathrm{~m}$ and each section of size $0.5 \mathrm{~m}$ (vertical) $\times 0.5 \mathrm{~m}$ (horizontal). The MCNP code supplies a relative error with the number of events recorded in a tally cell. In the calculations performed for Pelican, this relative error was lower than $5 \%$, except those that for which the dose rates were $<0.1 \mu \mathrm{Sv} / \mathrm{h}$. The total dose rates were evaluated as the sum of those resulted from each calculation performed with source 1 and source 2 respectively. The distances were defined by the Neutron Beam Guide Hall and instrument layouts.

\section{Results and discussion}

In the simulations performed, the neutrons were relatively easy to stop, the neutron dose rates around the Pelican monochromator assembly and $\mathrm{Pb}$ snout interface were reduced to $<0.5 \mu \mathrm{Sv} / \mathrm{h}$ by using $5-10 \mathrm{~mm}$ thick high density Boraflex ${ }^{\mathrm{TM}}$ on the inside wall surfaces, covering openings and lining the external surfaces of components. As well, using Boraflex ${ }^{\mathrm{TM}}$ at specific locations reduced the neutron dose rates around the Pelican instrument to $<0.5 \mu \mathrm{Sv} / \mathrm{h}$.

The gamma radiation resulted from the capture of neutrons by the Al-27 (and also, from decay of Al-28), in the material of - Al-windows (at entrance and exit guides), Optical System components, Sample and Detector Chambers' components and from the capture of neutrons by the monochromator and samples to be used in experiments. As well, from neutrons captured by cadmium and gadolinium in some of the components and also, from neutrons that are not reflected inside the guides but are absorbed by the boron containing glass. For thermal neutron capture by Al-27, the highest energy transition of gamma rays occurs at $\sim 7.7 \mathrm{MeV}$. Materials containing Boron-10 (e.g., Boraflex ${ }^{\mathrm{TM}}$ and borosilicate glass), used to attenuate the neutrons, when irradiated with low energy neutrons also emit photons of energy $0.48 \mathrm{MeV}$, but, these materials absorb a very small amount of gamma radiation. Therefore, a relatively thick $\gamma$ absorber has to be further added (outside of e.g., Boraflex ${ }^{\mathrm{TM}}$ ) and in the models presented here $\mathrm{Fe}, \mathrm{Pb}$ and a combination of $\mathrm{Fe} / \mathrm{Pb} / \mathrm{Fe}$ was used.

\subsection{MCNP simulations of shielding around the monochromator assembly and $\mathrm{Pb}$ snout interface}

The total $(n+\gamma)$ dose rate at the rear external surface of the monochromator shielding assembly, near to where the access door will be located, was $\sim 1.1 \mu \mathrm{Sv} / \mathrm{h}$. At other areas of the monochromator shielding assembly the total dose rates on the external surfaces were $\leq 2.5 \mu \mathrm{Sv} / \mathrm{h}$.

With the sample shutter open (similar to like running an experiment), the combined neutron and photon dose rates were noted to be much higher than $3 \mu \mathrm{Sv} / \mathrm{h}$ at external surfaces of the $\mathrm{Pb}$ snouts and guide shielding close to the monochromator drum beam opening. The major contributions to the dose levels could be due to the scattering arising from the Optical System components. At a distance of $4.9 \mathrm{~m}$ from the Optical System the dose levels were $<3 \mu \mathrm{Sv} / \mathrm{h}$.

Therefore, in order to meet the safety criteria persons 
will not be allowed to enter (via a safety interlock system) the experimental setup area when the shutter at the monochromator assembly is open to the neutron beam.

When the sample shutter is closed the dose rates near the beam opening reduce to $\leq 0.4 \mu \mathrm{Sv} / \mathrm{h}$.

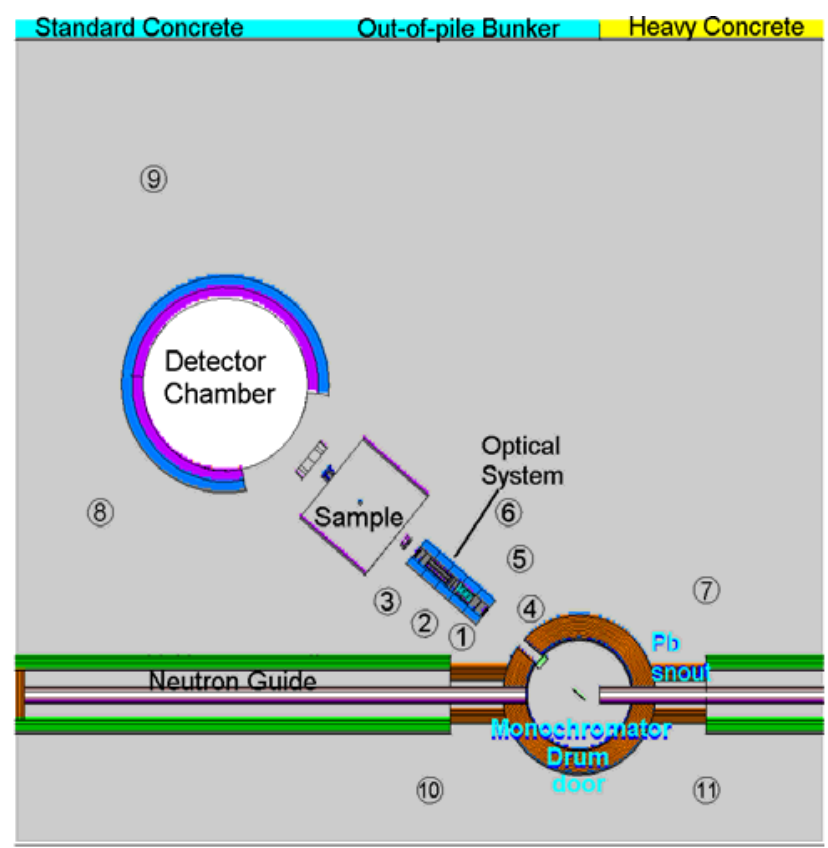

Figure 2. MCNP model showing the plan view of the Pelican instrument with shielding at the $40^{\circ}$ take off angle arrangement.

\subsection{MCNP simulations of shielding around the Sample Chamber and Detector Chamber Systems}

The simulations around the perimeter of the Sample and Detector Chambers' areas were performed with no installed shielding, except in the $90^{\circ}$ forward direction setup to the neutron guides the Out-of-Pile Bunker wall was modeled.

For the monochromator take-off angle at $40^{\circ}$ (the sample is located closer to the SANS bunker) the total dose rates at the external surface of the Sample Chamber and at a distance of $3.6 \mathrm{~m}$ from the Sample Chamber were calculated to be $<3 \mu \mathrm{Sv} / \mathrm{h}$. Similar results were obtained for the case of the take-off angle at $90^{\circ}$, the neutron and photon dose rates were calculated at a distance of $4.9 \mathrm{~m}$ left of the Sample Chamber. At the high take-off angle range limit of $140^{\circ}$, the total dose rates at the external surface of the Sample Chamber were $\sim 3 \mu \mathrm{Sv} / \mathrm{h}$.

In the areas behind the Detector Chamber at the Out-of-Pile Bunker wall surfaces (e.g., the $90^{\circ}$ take-off angle arrangement) the results indicated that the total dose rate was $\leq 2 \mu \mathrm{Sv} / \mathrm{h}$. The Out-of-Pile Bunker walls act as shielding for some of the experimental area perimeter, but not for the area towards the Pelican guide shielding sections and the Quokka instrument (located downstream on the CG1 neutron beam line). The results indicate that no shielding walls, like for example standard concrete, are necessary. However, to prevent persons from entering the area when an experiment is running it would be adequate for example to have a radiation shielding enclosure consisting of for example walls installed with bottom half gyproc and the top half with windows and an interlock system. Once in place, the radiation shielding enclosure should be thoroughly tested and if hot spots arise for different geometry settings of the instrument then additional shielding can be added or movable shields used.

Additional calculations were performed for positions $1-11$ given in Figure 2 (calculations were also performed for the $90^{\circ}$ and $140^{\circ}$ take off angle arrangements). Positions 1 and 4 are located very close to the monochromator drum opening, the total dose rate in this region was $\leq 400 \mu \mathrm{Sv} / \mathrm{h}$. Positions $2-6$ are next to the Optical System and the total dose rate was lower in these regions, for positions 2 and 5 the total dose rate was $\leq 110 \mu \mathrm{Sv} / \mathrm{h}$ and at positions 3 and 6 the total dose rate was $\leq 55 \mu \mathrm{Sv} / \mathrm{h}$. At positions $7-11$ the calculated dose rates were much lower, for position 7 the total dose rate was $14 \mu \mathrm{Sv} / \mathrm{h}$, at positions 8 and 9 the total dose rate was $\leq 4 \mu \mathrm{Sv} / \mathrm{h}$ and in the regions behind the monochromator drum and neutron guide shielding, positions 10 and 11 , the total dose rate was $\leq 0.5 \mu \mathrm{Sv} / \mathrm{h}$.

At the time the above simulations were performed MCNP 4B was the standard and validated code available, however, some of these results were checked with MCNP 5-1.40 and 5-1.60 [9, 10].

\section{Conclusion}

To meet the acceptance criteria and achieve radiological doses below the allowed limits, the shielding design for the Pelican instrument has been refined by means of MCNP calculations.

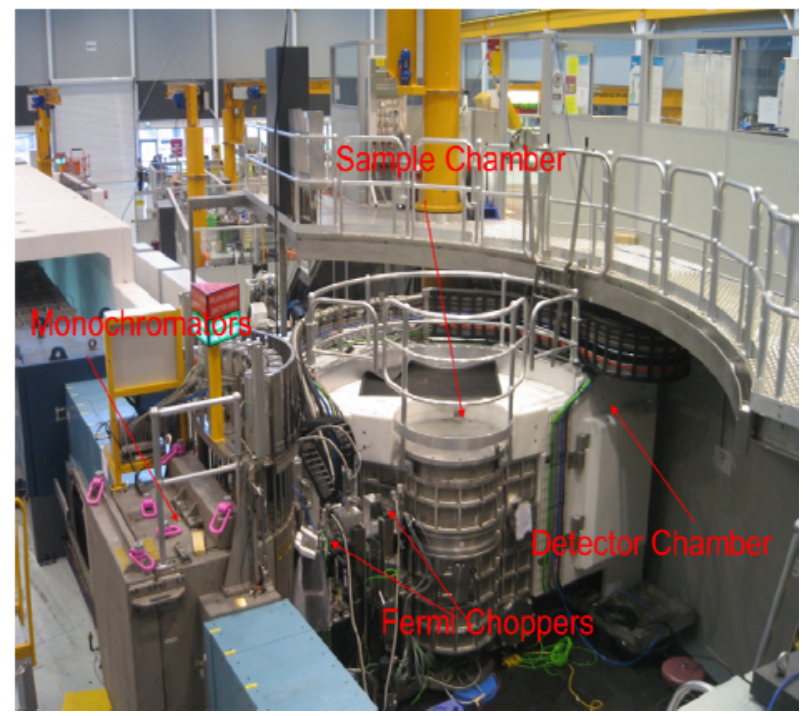

Figure 3. Current state of the Pelican instrument with the shielding arrangement. The instrument is in the hot commissioning stage. 
The latest shielding arrangement has confirmed the effectiveness of the design for the Pelican monochromator drum, a $\mathrm{Pb}$ snout interface, guide shielding and shielding around the Optical System, Sample Chamber and Detector Chamber Systems. The radiation shielding enclosure can consist of for example walls installed with bottom half gyproc and the top half with windows and an interlock system, to prevent persons entering the experimental setup area when the neutron beam is on. These arrangements are consistent with safety requirements, more than meets the floor load limit $\left(\sim 8\right.$ tonnes $/ \mathrm{m}^{2}<20$ tonnes $/ \mathrm{m}^{2}$ limit $)$, and cost constraints.

The current state of the instrument along with the shielding arrangement is shown in Figure 3. The instrument is in the hot commissioning stage.

\section{Acknowledgements}

This work was supported by the Neutron Beam Instruments Projects (ANSTO). The authors would like to thank Dr. D. Yu and T. Noakes from the Bragg Institute (ANSTO) for meaningful discussions and their valuable suggestions to the design of the shielding assemblies.

\section{References}

[1] D. Yu and R. Mole, Pelican instrument's specifications, fact sheet and applications, http://www.ansto.gov.au/research/bragg_institute/f acilities/instruments/pelican.
[2] Shielding requirements at premier neutron scattering facilities, ANSTO Document Number: NBIP-CL-400-0112, May 2005.

[3] Reactor Beam Hall and Neutron Guide Hall Deflection Analysis Results Report, ANSTO Document Number: RRRP-3220-EBECW-008-B, 31 July 2003.

[4] Private communication with D. Yu and T. Noakes, Bragg Institute, ANSTO.

[5] J.F. Briesmeister, Ed., MCNP ${ }^{T M}$ - A General Monte Carlo N-Particle Transport Code, Version 4B, LA-12625 -M, LANL, U.S.A., March 1997.

[6] ANS-6.1.1 Working Group, M.E. Battat (Chairman), American National Standard Neutron and Gamma-Ray Flux-to-Dose Rate Factors, ANSI/ANS-6.1.1-1977 (N666), American Nuclear Society, LaGrange Park, Illinois (1977).

[7] T. Ersez, G. Braoudakis and J.C. Osborn, Radiation shielding for neutron guides, Physica B 385-386 (2006), pp. 1268-1270.

[8] P. Willendrup, E. Farhi and K. Lefmann, McStas 1.7 - a new version of the flexible Monte Carlo neutron scattering package, Physica B 350 (2004), pp.E735 - E737. http://www.mcstas.org/

[9] X-5 Monte Carlo Team, MCNP ${ }^{T M}$ - A General Monte Carlo N-Particle Transport Code, Version 5 1.40, Report LA-UR-03-1987, LANL, U.S.A., April 2003 (Revised 10/3/05).

[10] F. Brown, B. Kiedrowski and J. Bull, MCNP 5-1.60 Release Notes, LA-UR-10-06235, LANL, U.S.A., 2010. 